\title{
La Argentina de Fabián Bielinsky: realidad e hiperrealidad en tiempos de crisis
}

Bértold Salas Murillo

Escuela de Estudios Generales

Universidad de Costa Rica

\section{Resumen}

Se analiza el retrato de la Argentina de principios del siglo XXI por el realizador y guionista Fabián Bielinsky en los largometrajes Nueve reinas (2000) y El aura (2005). Con distintas estrategias narrativas, estos filmes dibujan una sociedad corrupta y violenta. Además de examinar las características de la representación, el artículo aprovecha las diferencias narrativas para reflexionar en torno a las distintas formas de "representar" la realidad.

Palabras clave: Argentina, cine, metáfora, realidad, corrupción, violencia

\begin{abstract}
Argentina 's postrait at the beginning of XXIth century is analyzed by the producer and script writer Fabián Bielinsky in his movie picture Nueve reinas (Nine queens) (2000) and El aura (2005). By using different narrative strategies, these movie pictures depict a violent and corruptive society. This article examines not only their characteristics of representation but also their narrative differences to think about different ways of "representing" reality.
\end{abstract}

Keywords: Argentina, cinema, metaphor, reality, corruption, violence 


\section{Dos de Bielinsky}

A manece en una ciudad que, después lo sabremos, es Buenos Aires. Un hombre, joven, ocioso, desgarbado, fuma un cigarrillo y observa. Frente a él, un pequeño supermercado, uno de esos locales comerciales al lado de una gasolinera, que permanece abierto las 24 horas del día. Aspira el humo por una última vez, como para cobrar ánimos para la aventura y lanza el pitillo al suelo. Se dirige al establecimiento comercial a intentar una estafa. Así comienza Nueve reinas (2000), de Fabián Bielinsky.

Otro hombre, dormido, inconsciente o muerto, yace boca arriba. La cámara, en el nivel del suelo, apenas distingue el rostro y la mitad del pecho. Suena un persistente e hipnótico pip-pip-pip. Con dificultad abre los ojos; empieza a despertar y el plano se abre gradualmente, para mostrar desde arriba que está en la caseta de un cajero electrónico. El hombre se levanta, aún aturdido, toma el dinero y la tarjeta, y sale, al parecer acostumbrado a episodios como este. Inicia El Aura (2005), también de Fabián Bielinsky.

Nueve reinas y El aura: dos películas que, según propone el presente ensayo, muestran un mismo universo: Argentina, pero la Argentina de Bielinsky, una que a su vez está cosida al contexto de su producción y estreno. Ficciones que dan cuenta de una primera década del siglo XXI que recogió los frutos de tres décadas de contradicciones, convulsiones y violencia en el país suramericano. Estos fueron los únicos largometrajes que dirigió el argentino Fabián Bielinsky (1959-2006), antes de morir de un ataque cardíaco en São Paulo, Brasil: Nueve reinas, una historia de estafadores en Buenos Aires, y El aura, sobre el atraco a un casino en el sur de Argentina. Dos historias criminales cuyas fortalezas formales reposan en distintas bases: en el guion, en el caso del filme del 2000, y en la puesta en escena, en cuanto al del 2005.

Resulta interesante que historias que, como apunta este artículo, se sirven de tan diferentes recursos narrativos, sean responsabilidad de un mismo creador, Fabián Bielinsky, quien escribió y dirigió en solitario ambas películas. Dedicado principalmente a la realización publicitaria, Bielinsky tuvo una brevísima trayectoria en el cine, pues a estos dos largometrajes se agrega el cortometraje con que culminó sus estudios en el Instituto Nacional de Cine y Artes Visuales: La espera (1983), basado en el cuento homónimo de Jorge Luis Borges. A estos tres trabajos se suma que fue asistente y pulió su oficio con directores como Carlos Sorín (La eterna sonrisa de New Jersey, 1989), Marco Bechis (Alambrado, 1991), Eliseo Subiela (No te mueras sin decirme a dónde vas, 1995), Daniel Barone (Cohen vs. Rosi, 1998) y Alejandro Azzano (El secreto de los Andes, 1999), entre otros ${ }^{1}$.

Nueve reinas y El Aura son filmes 'convencionales', es decir que tienen por objetivo primordial el entretenimiento y despliegan una narración que en poco o

1 Inicialmente, este ensayo pretendió estudiar a Bielinsky desde la denominada 'teoría del autor' cinematográfico. Sin embargo, esta pretensión no resistió una segunda mirada: siempre es difícil tratar la autoría en el cine, al ser esta una narración que requiere la participación de numerosos artistas y técnicos; más complicado si se cuenta con apenas dos filmes de un mismo realizador para rastrear las constantes temáticas o estilísticas. 
nada se diferencia de cualquier otro que está legitimado por los hábitos de producción cinematográfica del Modo de Representación Institucional, que es el cine de Hollywood $^{2}$. Lo particular de ambas películas - y que es lo que incumbe a este texto- radica en la descripción de un mundo que irremediablemente se interseca con el contexto argentino, específicamente el que corresponde a los últimos años del siglo $\mathrm{XX}$ y los primeros del siglo XXI. Nueve reinas permite una reflexión en torno al que era percibido como el presente en la fecha de su estreno: una nación saqueada por ladrones, en la que la corrupción era la estrategia de sobrevivencia de todos sus habitantes. Un lustro después, El Aura mostraba al mismo país, aún melancólico y corrupto, a través de un realismo cuyos detalles se exacerban o ralentizan, de una manera que en el presente texto denominamos 'hiperrealismo'.

\section{La sociedad y sus relatos}

Como explica Sorlin, al producir un filme, los cineastas interpelan al público, y no a un público abstracto o futuro, sino "al espectador hipotético que los realizadores se dan, necesariamente, como testigo" (1985: 186). El cine construye una 'realidad' para este espectador, que es contrastada o que viene a confirmar con su propia y dinámica concepción del mundo. Los cambios en los imaginarios sociales son a menudo recogidos por las narraciones cinematográficas y difundidas entre el público, con el que establecen una relación dialéctica; de esta manera, juegan un papel

2 No en vano Nueve reinas fue muy pronto adaptada al contexto estadounidense, en el largometraje Criminal (2004), dirigida por Gregory Jacobs. en la memoria de sus espectadores y por tanto en el devenir histórico. Una narración cinematográfica es una 'puesta en escena social'. En esta, se da una suerte de redistribución: se "reorganiza, con elementos tomados en lo esencial del universo ambiente, un conjunto social que, por ciertos aspectos, evoca el medio del que ha salido pero, en lo esencial, es una retraducción imaginaria de éste" (1985: 169). En el filme es proyectado un mundo, a partir de personas y de lugares que pueden ser reales, así como de hechos verídicos; sin embargo, es 'proyectado', de la misma manera que "un volumen proyectado sobre una superficie plana se convierte en una forma que no es totalmente ajena al volumen y que sin embargo difiere de éste de manera esencial" (Sorlin, 1985: 169).

Este artículo propone que los argumentos de Nueve reinas y El aura - como también sus propuestas estéticas tan diferenciadas - son puestas en escena sociales que 'proyectan' los cambios experimentados por la sociedad argentina en las últimas tres décadas del siglo XX. Dichas mudanzas se sitúan en un contexto regional: en este tiempo América Latina padeció un período de desarticulación del modelo del Estado Benefactor, el cual justamente tuvo su apogeo en Argentina, con el proceso de privatización de las empresas públicas durante la administración de Carlos Menem (1989-1999) y en la consiguiente crisis económica, política y social con Fernando de la Rúa (1999-2001). Las reformas son señaladas como la principal causa por la cual Argentina pasó de tener un nivel histórico de desempleo que rondaba el $3 \%$ en 1974, a una desocupación abierta que superaba el $20 \%$ a mediados 
de 2002. Asimismo, que en la primera fecha cerca del $90 \%$ de la población laboral tuviera una cobertura cuasi plena de los derechos sociales, mientras que no más del $25 \%$ conservaba esos beneficios a comienzos del siglo XXI (Argumedo, Quintar, 2003: 620).

En Argentina, el proceso de desarticulación vino acompañado por un manejo corrupto de los organismos y los recursos públicos, el cual comenzó con la dictadura militar que se instauró en 1976, y se mantuvo en el poder hasta 1983. Explica Pírez que la dictadura no solamente desconoció las instituciones políticas, 'desapareció' a miles de personas, pretendió 'moralizar' y realizó una fuerte presión ideológica, "sino que inició la aplicación de una política económica que ha tenido continuidad luego de la recuperación institucional de 1983" (Pírez, 2002: 456). A partir de los 80 , la legitimación política e ideológica de la estructura de corrupción se hizo en nombre de las ideas neoliberales que se expandieron por América Latina en el marco de la crisis del marxismo.

Después de la administración de Raúl Alfonsín (1983-1989), llegó a la presidencia Carlos Menem, quien como candidato prometió un programa de recuperación productiva y reivindicación social, pero que al asumir el cargo: "hace explícitos sus acuerdos con el poder económico-financiero e impulsa las leyes de Reforma del Estado y de Emergencia Económica que conforman el marco jurídico necesario para profundizar la reestructuración socioeconómica del país" (Argumedo, Quintar, 2003: 617). Se da una acelerada privatización del patrimonio público, según valores que posteriormente fueron considerados muy bajos; explican Argumedo y Quintar que

La magnitud de los montos involucrados en las privatizaciones permitió que la corrupción adquiriera una dimensión sin precedentes en la historia del país tanto en términos de extensión en diversas áreas de la sociedad como en lo referido al volumen de la riqueza pública expropiada. La conjunción entre la crítica situación macroeconómica y el agravamiento del deterioro social, la corrupción que inunda las más amplias esferas de la sociedad, las crecientes críticas y movilizaciones populares en demanda de justicia, transparencia y mayor equidad social, unidos a una obscena exhibición del despilfarro de "ricos y famosos" asociados al poder menemista erosionan la gestión de Menem. (2003: 618)

Entre los múltiples casos de corrupción durante la administración de Carlos Menem destacan la privatización del gas natural con un quórum legislativo logrado por la presencia de falsos diputados - la prensa lo desenmascaró, pero la ley no fue anulada-, y la desaparición de una sentencia de la Corte Suprema de Justicia supuestamente promovida por el Ministerio de Economía (Pírez, 2002: 464). En ambos casos, se trata de un irrespeto a las instituciones públicas que no tuvo sanción.

Candidato de la oposición, Fernando de la Rúa llegó a la presidencia en 1999 con la promesa de 'reordenar la casa'. Sus 
resultados fueron fallidos tanto en el nivel político como económico y social, y el país sumaba cuatro años de recesión en el 2000. En mayo de este año, se realizó un paro general de protesta. En los siguientes meses, mientras se estrenaba Nueve reinas ( $31 \mathrm{de}$ agosto de 2000), la situación política se deterioraba aún más debido a las denuncias vinculadas con el pago de sobornos en el Senado para lograr la aprobación de la Ley de Flexibilización Laboral; estas involucran a senadores peronistas y radicales y a funcionarios cercanos al presidente De la Rúa. En las elecciones parlamentarias del 2001 se da un ausentismo inédito y una alta proporción de votos en blanco o expresamente anulados, en lo que se denominó 'voto bronca'. La expresión de esta rabia cobró una nueva forma en las jornadas de protesta de diciembre de 2001, cuando la demanda masiva fue "iQue se vayan todos!". Apuntan Argumedo y Quintar que aunque en la historia política argentina hubo casos y sospechas de corrupción, lo novedoso es la conformación de

una estructura de corrupción en la cual se articulan los grupos económico-financieros locales y externos más poderosos; una corporación político-sindical constituida por partidos y sindicatos que se entrelazan entre sí, ocupando los poderes Ejecutivo y Legislativo con la complicidad de un Poder Judicial encabezado por la Corte Suprema. (Argumedo, Quintar, 2003: 626)

Esa es la realidad que sustenta los filmes de Bielinsky. Como en todo texto fílmico, es posible leer en Nueve reinas y El aura una suerte de respuesta al contexto en el que fueron producidos y consumidos por miles de espectadores. En estos largometrajes se encuentran posibilidades de simbolización que se refieren a un momento específico: Argentina en el inicio del siglo XXI, después de tres convulsas y sufridas décadas.

\section{Historias criminales}

Nueve reinas narra el encuentro y las aventuras durante algo más de 24 horas de dos estafadores bonaerenses. Se ven unidos cuando el más veterano, Marcos (Ricardo Darín), rescata de un arresto al inexperto Juan (Gastón Pauls), tras su fallido timo en una tienda al lado de una gasolinera. El guion de Bielinsky y las interpretaciones de Darín y Pauls subrayan el contraste entre el estafador de raza y el que está porque no tiene de otra: el primero no duda en robar unos cuantos pesos a una viejecita; el otro, prefiere ganar el dinero sin herir ni hacer escándalo.

Tras decidir trabajar juntos durante un día, Marcos y Juan topan con la estafa de su vida: vender la falsificación de unas extrañas estampillas, las "Nueve reinas", al financista español Esteban Vidal Gandolfo (Ignasi Abadal). Cuando han acordado la venta, las falsas estampillas son robadas y deben comprar las verdaderas a un precio inferior del que pagará el español; para ello, recurren a los ahorros de Juan y al dinero de una herencia que Marcos robó a sus hermanos, Valeria (Leticia Bredice) y Federico (Tomás Fonzi). Vidal Gandolfo se encuentra hospedado en el mismo hotel donde trabajan los hermanos de Marcos; al enterarse del vínculo, exige una noche con la muchacha como condición para comprar las estampillas. Valeria accede, 
pero a cambio de que el hermano reconozca ante Federico que robó la herencia familiar. Vidal Gandolfo parte, deja como pago por las "Nueve reinas" el cheque de un banco que justamente ese día se declara en bancarrota. De esta manera, Marcos y Juan se quedan sin el dinero que invirtieron en las verdaderas estampillas. Abatido, Juan abandona a su socio y vuelve a su casa; allí se encuentra con sus socios: el falsificador de estampillas, el perito que fingió que eran verdaderas, la mujer que les vendió las verdaderas, los que se las robaron en motocicleta, el guardaespaldas de Vidal y el mismo Vidal; todos, jugando con las fichas de Sebastián, las Nueve reinas. Juntos, le ayudaron a embaucar a Marcos por unas falsas estampillas. También está su novia, Valeria, a quien entrega el dinero que timó al hermano.

Rodada cinco años después que Nueve reinas, El Aura es otra historia criminal narrada con un estilo muy distinto del picaresco guion y el realismo de la puesta en escena de la primera película. Cuenta una semana en la vida del taxidermista Esteban Espinosa (Ricardo Darín) quien, después de que su esposa lo abandona, acepta la invitación de un colega a ir de cacería a una región en el sur de Argentina, a 800 kilómetros de Buenos Aires. Espinosa es epiléptico y tiene una especie de don: una poderosa memoria y una imaginación para las tramas criminales que nunca ha sido puesta en práctica. Puede hacerlo ahora, porque mientras aprende a cazar mata accidentalmente a Carlos Dietrich, dueño de las cabañas donde se hospedan. Nadie se entera de esto, ni siquiera quienes viven aterrorizados por Dietrich: su joven esposa Diana (Dolores Fonzi) y el hermano de esta, Julio (Nahuel Pérez Biscavart). Cuando hurga en sus pertenencias, Esteban descubre que el muerto planeaba el atraco del blindado que carga el dinero del casino de la zona; sin conocer enteramente el plan, toma su lugar y lo explica a los socios venidos de la capital, Montero (Walter Reyno) y Sosa (Pablo Cedrón), así como a Julio. Sin embargo, Esteban no cuenta con toda la información necesaria y el atraco termina con una matanza y con Montero herido de muerte. Decidido a quedarse con el dinero, Sosa asesina a Julio y dispara a Esteban; sin embargo, cubierto por el bosque, éste consigue ser más rápido y lo mata. El atraco fue exitoso, en el sentido de que tiene el dinero, pero eso no parece interesarle. En las cabañas, encuentra que Diana ha huido. Una semana después de su partida al campo, de cacería, está de vuelta en Buenos Aires, sin más premio que el perro de Dietrich.

Nueve reinas y El aura son dos filmes que por su estilo narrativo difícilmente podrían atribuirse al mismo realizador. La forma de guiar el relato es muy distinta; las coincidencias se reconocen en el argumento, no en las propuestas estéticas, realista en Nueve reinas e hiperrealista en El aura. Tampoco son semejantes las preferencias del guion, también de Bielinsky: en el filme del 2000 abundan las alusiones al contexto argentino y los diálogos están colmados de chispeante humor; por el contrario, en el del 2005 no hay más que una cita a la situación del país - “Aquí todos roban”, dice Esteban al colega que después lo invitará a la caza - y los parlamentos se caracterizan por su gravedad. Difícilmente, los escenarios podrían haber sido más distintos: la ciudad, en Nueve reinas, y el bosque, en $E l$ 
aura, aunque en ambos casos son espacios intimidatorios, traicioneros y violentos.

La diferencia esencial entre Nueve reinas y El aura es de estilo, expresado en la puesta en imágenes y en las preferencias del guion. Los argumentos, en cambio, coinciden en una temática criminal que es desglosada cual si fueran las piezas de un rompecabezas. Ambos filmes están dedicados a delincuentes: inexpertos, como Esteban, en El Aura, o de poca monta, como Marcos y Juan, que se encuentran repentinamente con un trabajo realmente grande. Tampoco es delincuente "de profesión" el incorpóreo Dietrich, quien trama el atraco para saldar sus deudas con el mismo casino, y la estrella de Montero y Sosa no es tampoco demasiado brillante, pues participan del "trabajo" para pagar sus deudas con el Turco (viejo conocido de Dietrich). Estas características, que dan cuenta de un mundo fundamentalmente criminal, pueden asociarse a la historia argentina; explican Argumedo y Quintar que a partir de los 80 hubo una importante 'mano de obra' desocupada, antes integrante de las fuerzas de seguridad de la dictadura militar, que participa durante las siguientes décadas del tráfico de drogas, robos, asaltos, secuestros y similares. Estos sectores “están en su gran mayoría respaldados por las estructuras de corrupción nacionales o provinciales con las que intercambian favores de impunidad" (Argumedo, Quintar, 2003: 627).

El argumento y la puesta en escena de Nueve reinas y El aura señalan mentalidades y prácticas sociales particulares. Explica Pírez que las dictaduras militares recurrieron a una violencia física que se prolongó en "violencia ideológica para determinar, no solamente los comportamientos, sino aun los modos de pensar y entender la realidad (de allí la censura y la represión del pensamiento)" (Pírez, 2002:459). A partir de los 70 se da lo que Pírez denomina un cambio sociocultural, el cual resume:

Lo importante, una vez más, era solamente el logro, no cómo se llegaba a ello. De allí que fuera preciso aceptar la corrupción, la superficialidad, el debilitamiento de las normas sociales, como también la pobreza y la exclusión, que alguna vez se recuperarían gracias a la "derrama" tantas veces anunciada y nunca producida. Lo que ocurrió sería, para parafrasear a Barbara Tuchman, una "marcha de la locura" colectiva: la sociedad siguió hacia el vacío cuando algunas voces, débiles, pero que podían oírse, lo anunciaban. Esa debilidad de lo público es dramáticamente evidente en la producción de las ciudades argentinas y especialmente en su ciudad principal, Buenos Aires. (Pírez, 2002: 465)

Buenos Aires, escenario de Nueve reinas, condensa esa sociedad que niega los intereses colectivos y se dirige al vacío. Una sociedad que es, además, un enigma para sus habitantes, quienes optan por una sobrevivencia que no repara en sus medios. En este sentido, como fue apuntado, los dos largometrajes son rompecabezas para el espectador. En Nueve reinas, esto se da de forma velada, pues la narración presenta a Marcos y Juan, quienes pretenden efectuar una elaborada estafa, y al mismo 
tiempo da pistas para que finalmente descubra que el estafado es Marcos. Funciona de manera más explícita en El Aura, en la que el descubrimiento y acomodo de las piezas - el atraco urdido por Dietriches guiado por las intuiciones de Esteban. La de Nueve reinas es, en principio, una propuesta realista, en el sentido de que narra una historia sin hacer uso de recursos formales que modifiquen las expectativas del espectador respecto a la naturaleza del mundo. El Aura, en cambio, presenta una atmósfera en la que los detalles son subrayados: la mirada de Esteban, hilo conductor del relato, se extravía, como lo hace la misma cámara, de manera que en determinados pasajes parece como si fuera alguien que participa en el sueño de otro.

\section{Las realidades de Fabián}

Como fue señalado, pese a las diferencias estilísticas, la exposición del argumento es bastante similar en Nueve reinas y El Aura. Los personajes que introducen las historias, Juan y Esteban, son observadores que se tornan protagonistas: dos tipos que no están en lo suyo, el crimen, o al menos así los presenta el relato. Juan se mete a estafador para conseguir el dinero que libere a su padre de la cárcel; por su parte, Esteban es un aspirante a delincuente: posee agudeza para lo criminal, pero nunca se ha dedicado a esto y cuando lo hace, parece ser por curiosidad o juego. Juan se dedica a aprender las artes del estafador experto, Marcos; Esteban es, más claramente, un observador de un mundo de oportunidades para el crimen que decide convertirse en participante. Hay un tercer observador: el perro de Dietrich, quien reconoce el olor de su amo en Esteban, su asesino, y en cuyos ojos se fija el último plano de El Aura. Ambos personajes, Juan y Esteban, son la puerta para que el espectador descubra la historia: son los que dan las pautas del contrato entre el relato cinematográfico y el público; es a partir de ellos que el relato se postula como realista en Nueve reinas, e hiperrealista en $E l$ Aura, con la lucidez que precede al ataque epiléptico como frecuencia.

Pese a su realismo, Nueve reinas es una prolongada impostura, que comienza al postular como protagonista a Juan. El verdadero personaje principal es Marcos, cuya conducta es valorada y, finalmente, manipulada por la telaraña tejida por el falso aprendiz. Manipulación que también afecta al espectador, quien no se entera hasta la última secuencia de que Marcos, el más inescrupuloso ladrón, está siendo embaucado. En el desenlace se revela una compleja representación en la que todos los personajes tienen una máscara, salvo el que suponemos el único falso, Marcos; incluso el inocente Juan resulta llamarse Sebastián, como dijo a Marcos que quería llamarse - iserá este su nombre, realmente?-, y concluye su participación con una nueva mentira, la invención de un pasado para el anillo que obsequia a su novia. Nuevamente: el de Nueve reinas es un realismo de lo falso, un seudorrealismo, pues consiste en la puesta en escena de una farsa, que se muestra como tal solamente en el desenlace.

La realidad es puesta en entredicho en ambos filmes de Bielinsky. En Nueve reinas, no es la que Marcos y los espectadores creen: todo es una escenificación, una comedia que los engaña. En El Aura, la puesta en escena está al servicio de una 
conciencia o mente vaporosa, inestable como la de Esteban. Es decir, en los largometrajes de Bielinsky se presentan falsas realidades: la percepción de Esteban o la información que conoce Marcos; incompleta o errónea, tanto para ellos, como para el espectador, que comparte su perspectiva. La realidad es 'confusa' — una trama que se hace cada vez más compleja - en Nueve reinas, y 'difusa' — la inestabilidad mental de Esteban como intermediariaen El Aura.

Durante el visionado de un filme, la noción de realidad propuesta por el relato audiovisual dialoga con la del propio espectador. En el caso de los filmes de Bielinsky, el primer público fue el mismo pueblo argentino. De esta manera, en Nueve reinas, la idea de una Argentina de bribones es subrayada continuamente por los diálogos y el argumento. En El Aura, por el contrario, impera la perspectiva de Esteban, un epiléptico, quien mantiene un vínculo con la realidad caracterizado por el extrañamiento. En ambos casos, una farsa o una suerte de sueño, se trata de la 'Argentina de Fabián', expresión de un estado de ánimo que fue compartido por miles de argentinos a principios del siglo XXI.

\section{La Argentina de Fabián}

Para comprender mejor esta 'Argentina de Fabián' hay que recordar que durante las últimas décadas el país suramericano experimentó lo que Pírez denomina una 'crisis sociocultural'. El principal rasgo de esta crisis fue la fragilidad de las instituciones públicas, tanto estatales como sociales, para construir comunidad $\mathrm{y}$ fungir como puntos de referencia en la cotidianidad. Explica Pírez que esta crisis se caracterizó por la:

debilidad para producir acuerdos, normas colectivas que organicen el comportamiento y, particularmente, que permitan la formación de organizaciones que desarrollen intereses generales. Se trata, en otra dimensión, de una fuerte debilidad de lo público (...). En suma, la dificultad de subordinar los intereses particulares, las posiciones parciales a los intereses generales, a los bienes y necesidades comunes. En otra perspectiva se trata de la radical debilidad del Estado, entendido como el responsable frente a la sociedad civil de gestionar lo que es común, lo que es de todos, los intereses generales, 'lo público. (Pírez, 2002: 463)

Un filme propone al espectador una visión de mundo, consistente en una serie de rasgos axiológicos e ideológicos en la representación; tanto en Nueve reinas como en El aura, esta retrata una sociedad donde lo público se ha deteriorado y las instituciones se han desmoronado. Además, es posible diferenciar entre las expectativas ideológicas y axiológicas de los personajes, y las del mismo relato fílmico. En Nueve reinas, coinciden la cosmovisión de Marcos y la de la narración: Argentina es tierra de estafadores; asimismo, el cinismo y la melancolía, dos maneras de afrontar un mundo caracterizado por la aridez moral, son representadas por los personajes principales: el cínico es Marcos, y el melancólico, Juan. Por su parte, en El Aura, el desmoronamiento de los referentes es retratado por medio de un protagonista 
que se relaciona con dificultad con la realidad, y cuando lo hace, es por su fascinación por el mundo criminal.

En Nueve reinas, Marcos insiste en que en Argentina todos roban y estafan, además de que tienen su precio; no hay diferentes calidades morales, solamente diferencias en cuanto al coraje o malicia para delinquir o el precio que pone a la dignidad. Como respuesta, Marcos pretende ser más astuto e inescrupuloso que cualquiera. Cuando Vidal Gandolfo pide acostarse con Valeria como condición para comprar las estampillas, Marcos está seguro de convencerla: "No hay santos, lo que hay son diferentes tarifas"; después, afirmará, tras preguntar a Juan si se acostaría con un hombre por dinero: "Putos no faltan, lo que faltan son financistas". Si no estafa, Marcos roba, incluso lo que no necesita: una cajetilla de cigarros, aunque no fume; y un chocolate, de Grecia: importado aunque "este país se va para la mierda", afirma. Roba el diario y cuando Juan le pregunta si no puede comprarlo, responde: "Claro que puedo comprarlo, como puedo no comprarlo, como harían todos si pudieran". Justifica el robo de la herencia familiar a su hermana: "Fui más rápido que ella, nada más... Ella haría lo mismo". Su comportamiento conlleva que la narración sea un enigma para el espectador, quien no sabe qué esperar de Marcos; después de cerrar el trato con Vidal Gandolfo, Juan dice: "Me estás cagando, no sé cómo pero me cagás". El filme no desmiente esta pesimista versión del presente argentino, más bien acuerpa sus afirmaciones, cuando el mismo Marcos es estafado. Puede anotarse, sin embargo, que muchos de los que participan en la farsa (sus viejos socios el Turco y
Sandler, Valeria, el empleado bancario), lo hacen como una venganza.

Más allá de las palabras de Marcos, lo cierto es que en Nueve reinas ni un solo personaje es honesto o dice la verdad: los que no son delincuentes, son farsantes. Al restaurante que funciona como oficina de Marcos llega un vendedor con artículos robados o de contrabando: chequeras, teléfonos, relojes; sin embargo, afirma: "Yo no soy un delincuente". Un cómplice de Marcos aparece con una credencial policial; según le explica Marcos a Juan, se la venden en la delegación junto con el arma. El supuesto perito filatelista reconoce que las estampillas son falsificadas, pero no informa a Vidal Gandolfo para pedir una parte a Juan y Marcos; ellos se resisten y finalmente le piden una tarjeta para llamarlo cuando tengan su parte: "Entre los delincuentes la cosa funciona así: en confianza", dice el segundo. Por si fuera poco abundan los planos de la calle, de un espacio urbano colmado de gente que, según es descrita y enumerada por Marcos, solo piensan en el robo o la estafa: "Están ahí, descuidistas, arrebatadores, gallos viejos". Personaje de ficción dentro de la ficción, el corrupto financista Esteban Vidal Gandolfo viene a caracterizar la Argentina de los 90: "Voy a extrañar vuestro país. Nunca he visto mejor disposición para los negocios”.

Sin duda, Nueve reinas sintonizó con las inquietudes de la sociedad argentina y la imagen que esta tenía de su presente: el saqueo de las instituciones públicas, el desprestigio de la clase empresarial y política y la crisis económica (que culminó en el famoso "corralillo") que no supo enfrentar el gobierno de Fernando De La Rúa. Premonitorio, el 
filme presenta en su desenlace una situación que se haría frecuente al año siguiente a su estreno y que culminó con la revuelta popular y la renuncia de De la Rúa en diciembre de 2001: el cierre de instituciones financieras y el congelamiento de los depósitos bancarios de la clase media.

También hay una metáfora de Argentina en El Aura, en este caso como tierra de extrañamientos: el resultado de más de tres décadas de violencia y derrumbe de las instituciones y los referentes. De allí el hiperrealismo, la particular aproximación a la realidad de El Aura: Esteban es un hombre que observa el mundo como un extraño, como si este fuera ajeno a él. Así se aísla de la gente, ve a su esposa partir, se suma a una excursión de caza, asesina accidental y deliberadamente $y$ participa en un atraco; siempre, como un extranjero en la realidad. A mitad del largometraje es testigo de un asalto, el de la fábrica de Cerro Verde: presencia la entrada de los asaltantes, escucha la balacera y después sigue en automóvil y a pie a un moribundo Vega, quien iba a participar en el atraco al casino. Con serenidad, como quien observa a uno de sus animales disecados, lo ve morir: se entiende mejor con las naturalezas muertas. Esteban cuenta a Diana que en los minutos que preceden a un ataque epiléptico, se abre "una puerta en la mente"; es una forma distinta de la conciencia: voces, imágenes y olores nuevos, o percibidos de una manera completamente diferente.

El presente argentino también se revela en el tratamiento del tiempo en Nueve reinas y El aura. En el filme del 2000, los personajes recuerdan continuamente lo pretérito, aunque este es generalmente un pasado inventado, en ocasiones elaborado según lo exigen las circunstancias y con la estafa como objetivo. Hay una constante falsificación de la memoria: Sandler muestra a Marcos una noticia respecto a un financista español que no existe, como tampoco existen las extrañas estampillas que codicia. Es a partir de otra falsa prueba de la memoria, las fotografías de un abuelo en Polonia, que convencen a la esposa de Sandler de que les entregue las estampillas. Y para el anillo que regala a Valeria, fruto de una de sus estafas, inventa que ha pasado casi cien años con su familia.

En Nueve reinas, el paso del tiempo marca el semblante de Juan, tristísimo por el encarcelamiento de su padre — quien le enseñó a estafar, aunque después se arrepintió- y por la corrupción que encuentra en Argentina y de la que participa. Con persistencia, tararea, pregunta y trata de recordar las notas de Il ballo del mattone, de Rita Pavone, una canción utilizada en un viejo filme argentino. El pasaje más ejemplar de esa melancolía marcada por el recuerdo de la inocencia infantil perdida es cuando en el metro compra la postal de un caballero medieval, y al niño que la vende lo pone a escoger como pago entre un billete y un carro de juguete; el chico escoge el primero: el lucro antes que la inocencia.

En El Aura, en cambio, el tiempo es un componente central de la sustancia narrativa: en diferentes secuencias, la música y las imágenes se ralentizan, los pasajes se repiten con fugacidad en la mente de Esteban. Se construye, así, una noción de tiempo que transcurre de una manera por completo extraña a los personajes que lo 
viven: estos parecen observadores o pacientes, antes que agentes de su tiempo, como lo fue el pueblo argentino respecto al paulatino deterioro del tejido social en las últimas décadas del siglo XX.

\section{Últimas palabras}

Nueve reinas y El aura participaron - podría decir incluso que lideraron - la revitalización estilística y comercial del cine argentino en los primeros años del siglo XXI. Sin dejar de cumplir su propósito primordial de entretener, dibujan un universo diegético marcado por la corrupción, el crimen y la falsificación del pasado y el presente, que en el presente artículo se ha vinculado con el contexto argentino de los últimos años del siglo pasado. Dirigidos a un 'espectador hipotético', el pueblo que vivió este período de fuertes cambios, ambos filmes constituyen la puesta en escena social de un estado de ánimo, en un caso a partir de una estética realista - aunque el argumento revele la falsedad de esta realidad-en Nueve reinas, y de una hiperrealista en El aura. Como cualquier producto cultural latinoamericano, son un material rico para estudio humanístico y sociológico de la región.

\section{Bibliografía}

Argumedo, Alcira; Quintar, Aída. "Argentina ante una encrucijada histórica", en Estudios Sociológicos, Vol. 21, No. 63, 2003 El Colegio De México.

González Acevedo, Juan Carlos. Che, qué bueno que vinisteis. El cine argentino que cruzó el charco. Barcelona, Diéresis, 2005.

Pírez, Pedro. “¿Qué pasó en la Argentina? Algunas piezas de un rompecabezas para intentar entender". En Estudios Sociológicos, Vol. 20, No. 59 (May Ago, 2002). El Colegio De México.

Sorlin, Pierre. Sociología del cine. México: Fondo de Cultura Económica, 1985.

\section{Filmografía}

El Aura. Producción: Mariela Besuievski, Pablo Bossi, Samuel Hadida, Gerardo Herrero. Realización y guion: Fabián Bielinsky. Argentina, 2005.

Nueve reinas. Producción: Pablo Bossi. Realización y guion: Fabián Bielinsky. Argentina, 2000. 